\title{
Wealth Breeds Decline: Reversals of Leadership and Consumption Habits
}

\author{
LIONEL ARTIGE \\ Department of Economics, Universitat Autònoma de Barcelona, Spain \\ CARMEN CAMACHO \\ Department of Economics, Université catholique de Louvain, Belgium
}

DAVID DE LA CROIX*

FNRS, Department of Economics and CORE, Université catholique de Louvain, Belgium

In a two-region model, we formalize Kindleberger's idea that wealth breeds first more wealth, and then decline: when one region leads, its inhabitants develop consumption habits incompatible with the necessary investment in knowledge to remain the leader. This gives the other region a window of opportunity to gain economic primacy. The theory suggests that differences across regions that have similar characteristics may persist even if physical capital flows from rich to poor regions. We study patterns of overtaking, alternating primacy, irreversible decline, and monotonic convergence, according to the initial dispersion of knowledge and the strength of consumption habits. Even though exogenous factors may matter on some occasions, we show that they are not necessary to reverse economic leadership.

Keywords: consumption habits, over-taking, regional primacy, capital mobility

JEL classification: R110, O410, E210, N100

\section{Introduction}

Benchmark neo-classical growth models predict that per capita incomes of regions that are similar in their structural characteristics converge with one another in the long run independently of their initial conditions (Galor, 1996). This view seems to be broadly supported by recent data (e.g. Barro and Sala-I-Martin (1991)), although the estimated pace of convergence is rather slow. Over longer periods, however, historical data show a great divergence. Moreover, even among regions that do converge, the process is neither smooth nor monotonic, and reversals of

* Address for Correspondence: David de la Croix, Department of Economics, Place Montesquieu 3, B-1348 Louvain-la-Neuve, Belgium 
leaderships are frequent. The recent literature "from Malthus to Solow" has stressed this point. Galor and Weil (2000), followed by Hansen and Prescott (2002) and many others, model the mechanisms behind the early take-off of the Western World. Their framework helps understand the differential timing of takeoff, which generated the phenomenon of the great divergence between rich and poor countries we observe today (Pommeranz, 2000). Patterns other than simple take-off are also observed: regions overtake and surpass others in economic leadership, and regions being caught up with may in some cases decline absolutely. In some other cases, they can have a rebirth (Landes, 1998). Strikingly, even among regions that are characterized by extensive capital mobility, economic primacy may alter and reversals of fortune may take place.

Reversals of fortune are often modeled as a consequence of adverse exogenous shocks: wars, climate change, discoveries, etc. Some authors, however, argue that endogenous mechanisms may also be important to understand leapfrogging and other non-monotonic changes in relative income. For example, Kindleberger (1996) defends the view that economies, like human bodies, go through a life cycle along which "vitality" varies, depending on how entrepreneurial each generation is. The Venetian Maritime Republic declined when leaders started devoting more time to consumption rather than investing in the improvement of shipping techniques, the discovery of new routes, etc. In the words of Dudley Carleton, the British ambassador to Venice in 1612: "They here change their manners... Their former course of life was merchandising; which is now quite left and they look to landward buying house and lands, furnishing themselves with coach and horses, and giving themselves the good time with more show and gallantry than was wont...." (Burke (1974, p. 128)). Florence provides another example. Its famous banking sector declined when Lorenzo the Magnificent delegated power over the Medici bank branches as he turned to the high life. One way to capture the idea that rich regions tend to rest on their laurels, and are inclined to favor consumption over investment in knowledge, consists in introducing habit formation in an otherwise standard regional growth model. This implies that describing the state of a region by its stocks of physical and human capital is not enough to understand its economic superiority over others. One also needs to look at the stock of consumption habits, or, stated otherwise, at standard-of-living aspirations.

Our model economy consists of two regions or two countries where physical capital is perfectly mobile. Both regions produce the same commodity with the same technology and have the same preferences, although they may have different initial levels of knowledge. Along their growth path, regions differ in the stock of consumption habits - or standard-of-living aspirations - that is built from the previous generation. In other words, each generation's propensity to consume depends positively on what their parents consumed. At some point in a development process, the young generation of the richer region develops living standards that are incompatible with the necessary investment in knowledge to remain the leader. This reduces the growth rate in comparison with the other region. At some point in the decline process, consumption is low again and a new growth cycle may start. This process may or may not end in regional convergence. 
This set-up has two major implications. First, reversals of fortune do not necessarily rely on exogenous shocks. Although exogenous shocks can be important in certain cases, they are not necessary to account for reversals of leadership. Second, convergence is not guaranteed even when capital is perfectly mobile across regions and countries.

In the literature, different approaches have been followed to explain regional income dynamics, all relying on the interaction between divergence forces and convergence forces. The new economic geography approach stresses the role of increasing returns to scale and low transportation costs to account for the presence of economic agglomerations. Contrary to standard growth theory, "catastrophic" agglomeration prevails, not convergence. This is especially true if physical capital is mobile (see for example Desmet (2002)). Although this view successfully accounts for the growth of large poles of development, it falls short of explaining why the periphery does not decline irreversibly, losing all its main input in favor of the core. A response to this shortcoming is proposed by Ottaviano et al. (2002). They study cases where agglomeration generates urban costs hindering the overwhelming growth of the core. Examples of these costs are land rents and commuting costs. When these costs are added, their model is able to produce the pattern dispersion/agglomeration/re-dispersion. Although this setup provides richer dynamics than the standard economic geographic model, it does not allow for the repetition of this pattern over time. This means that the core will never rebound unless an exogenous change occurs. This is generally how leapfrogging is modeled in otherwise stationary models. For instance, Brezis et al. (1993) assume that a new technology becomes suddenly available in the world economy. The rich region has little incentive to adopt it because it loses its accumulated experience and must spend some time learning how to use the new technology. As for the poor region, if it has little experience in the old technology, it will adopt the new one, catch up with its neighbor, and eventually take the leadership.

An emerging alternative view considers that institutions, understood in a broad sense, are a key determinant of income differences and reversals. Differences in institutions in turn, can be partly explained by geographical factors such as the presence of natural resources or climate. Acemoglu et al. (2002) argue that relatively rich countries colonized by European powers in 1500 are now relatively poor and vice versa. They explain this reversal of fortune by the types of institutions imposed by the European settlers. "Extractive" institutions were introduced in the resource rich countries, benefiting the settlers rather than the countries. In the relatively poor areas, no plundering incentives existed to prevent the building of investmentfriendly institutions. As a result, the decline or rise of those countries is rooted in a major - exogenous - institutional difference linked to colonization. Climate can also play a role. When it was settlers-friendly, the Europeans built states with similar institutions as those in Europe. A similar argument is invoked by Lagerloef (2004) to explain reversal of fortune across US states. Warmer states developed a type of farming requiring slave labor. When slavery was abolished, those states were severely hit and surpassed by colder states, whose economic activity was relying on free labor. Besides the nature of institutions, the ancientness of a state 
may also promote its economic development, through learning-by-doing. This implies that initial advantages may persist, which play against reversals of fortune. Bockstette et al. (2002) find supportive evidence for persistence of initial advantage in a cross-section of countries over the last 30 years. Considering longer periods of time, the history of statehood may nevertheless lose explanatory power. Ethiopia, the oldest state in subsaharian Africa is among the poorest in the region.

A major step towards endogenizing the overtaking is made by Galor et al. (2002). They build a model with human capital where a country can overtake a richer one if it is initially endowed with a more equal distribution of land. When some landlords own a large fraction of the land in the economy, they impede human capital accumulation opposing education policy. ${ }^{1}$ An advantage of this setup is that overtaking depends on initial conditions and not on exogenous shocks.

The paper is organized as follows. Section 2 illustrates and discusses some historical examples of decline and alternating primacy. The model is introduced in Section 3. Regional dynamics are analyzed in Section 4. The role of capital mobility is explicitly studied in Section 5. The role of conspicuous consumption in shaping future rise and decline is illustrated in Section 6. Section 7 concludes.

\section{Historical Evidence}

Historical evidence suggests that economic development is anything but linear. This holds at world level, within continents and within countries.

In the fifth century, the fall of the Western Roman Empire and its defeat by scattered tribes mark the end of European economic primacy to the benefit of the Middle East and Asia. Whichever cause is argued, ${ }^{2}$ this defeat would never have been possible if this powerful empire had not decomposed internally, leaving the many with "no bread" and giving the few "too many games": physical and human resources were allocated to entertainment instead of investment in knowledge and infrastructure. The economic decline of Europe turned out to be overwhelming until the 15th century. Thereafter, Europe experienced a long wave of economic rebirth and other zones, like the Muslim world, declined.

The history of regions is not more linear. The demographic fluctuations of cities, considered as a proxy for regional economic activity ${ }^{3}$ witness waves of development and decline. Amalfi, in Southern Italy, was the largest Italian city-state in the 10th century with $60,000-80,000$ people. Now it is a small town of 7000

1 A similar idea is put forward by Engerman and Sokoloff (2002) to explain the role of initial inequality in shaping the development of New World economies.

2 The first comprehensive survey of the causes of the decline is by Gibbon (1788). In the recent book by Schiavone (2000), the roots of the decline are to be found in the behavior of the aristocracy, preferring luxury to investment, and leisure to work.

3 Bairoch (1991) and Acemoglu et al. (2002) also use size of cities as a proxy for GDP per capita. The recent paper by Henderson (2003) helps to precise the link between the two. He develops a model where there is a growth-maximizing level of urban concentration, which is contingent on the size of the country and the level of development. 


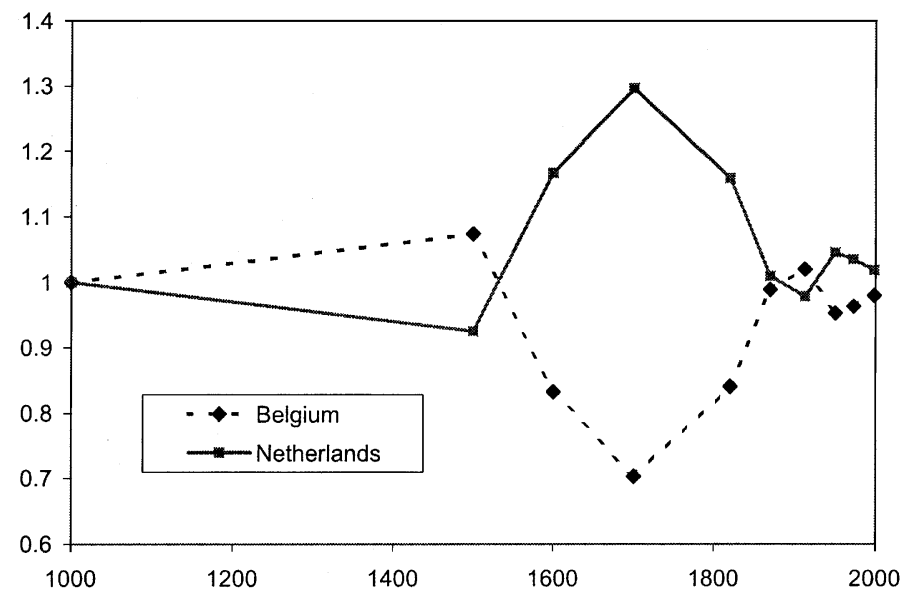

Figure 1. GDP per capita.

inhabitants while Naples, a neighboring and competing city-state to Amalfi in the Middle Ages, now has more than one million inhabitants. In the Middle Ages Southern Europe was more prosperous and literate than the North. In the 11 th century Cordoba had 400,000-500,000 inhabitants, Palermo 350,000 and Seville 100,000. At the same time, Paris and London had 20,000-25,000, (see Bairoch et al. (1988)). Then the South lost its primacy. Between the 15 th and 19th centuries, the economic center of gravity in Europe successively moved from Italy to Spain and Portugal, then to the Netherlands. Finally, England became the great economic power while Portugal, Spain and Southern Italy were already lagging far behind.

These different economic development patterns are often explained by several "exogenous" factors: big cities and high level of incomes can be favored for example by the proximity of the sea (Rappaport and Sachs (2003)), and primacy can be lost through invasions, war, climate change, institutions, technology etc. Kindleberger (1996) argues that some of these factors may have ultimate economic causes: bad political decisions may be taken when the quality of institutions has deteriorated following a lack of investment by the elite. The inability to maintain competition also stems from a loss of interest by leaders. The development pattern of the territories that are now Belgium and the Netherlands provides a good example of this mechanism. Figure 1 reports the GDP per capita, normalized by the mean, from Maddison (1995). Figure 2 reports the relative population of big cities, as a share of the tota1. ${ }^{4}$ These figures have been built so as to remove all scale effects,

4 Source: Bairoch et al. (1988) for 1000-1850 and "populstat" website by Jan Lahmeyer for 19002000. Big cities (those that amounted to had 50,000 inhabitants or more at some point before 1850) are Antwerp, Bruges, Brussels, Gent and Liege in Belgium; Amsterdam, Leiden, Rotterdam, 'S Gravenhaegue in the Nertherlands. 


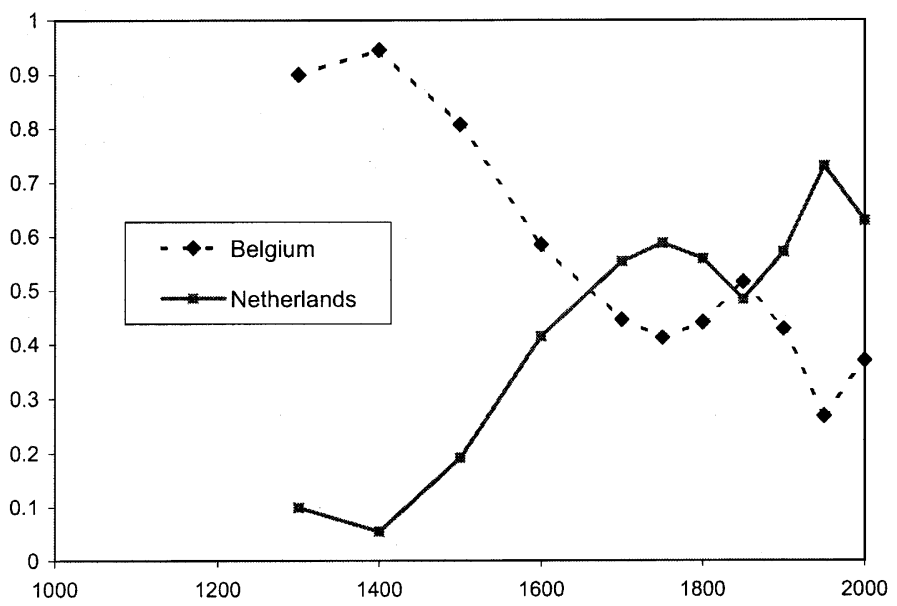

Figure 2. Population of big cities.

detrending each series by the sum of the two. One series is thus by definition the symmetric of the other. When series intersect, there is a reversal of fortune, i.e. one country takes over the other one. Before 1500, Belgium was clearly leading, with flourishing cities like Bruges and Antwerp. Then Bruges, followed by Antwerp, declined and Amsterdam rose. The real force behind the decline of Bruges was its inability to meet the competition, because of the increasing conservatism of Bruges traders and bankers (Kindleberger 1996). The decline of the Netherlands in the 18th century is related to the same kind of behavior (see Section 6). After the Dutch decline, Belgium caught up and overtook its neighbor, thank to a faster industrialization. Then, in the 20th century, Belgium did not manage to maintain its primacy, and the Netherlands experienced a re-birth compared to Belgium.

Figures 3 show other examples of alternating primacies involving border regions: Vienna versus Prague and Naples versus Sicily (Palermo + Catania + Messina). Alternation is particularly striking given that capital is likely to be mobile and should have enforced either convergence (in case of decreasing returns) or coreperiphery agglomeration.
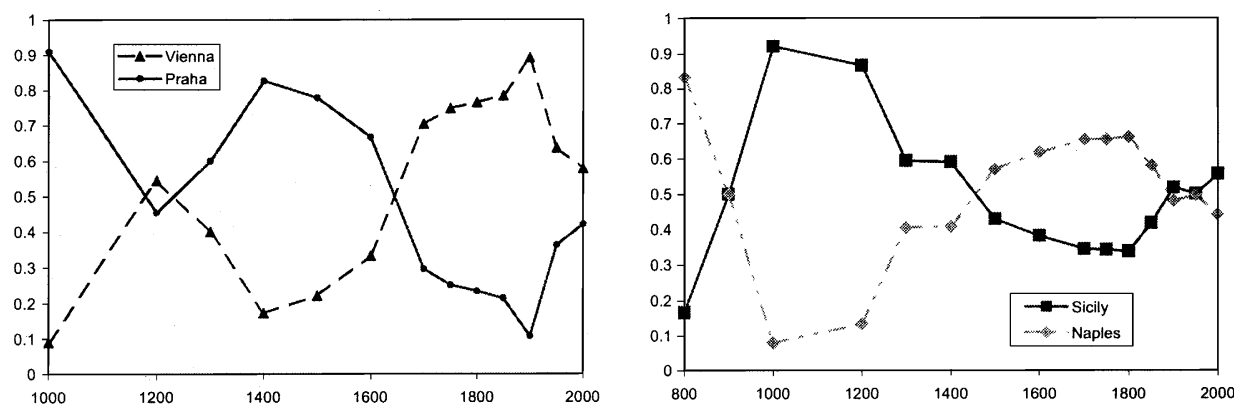

Figure 3. Population of big cities. 


\section{A Simple Model of Reversal}

Our model is an overlapping generations model with physical capital and knowledge. It describes an economy with two regions, $A$ and $B$, in which generations live for two periods. For the sake of simplicity, the growth rate of the population is zero and the size of the regional population is normalized to one. In the first period of their life, households work, consume and invest a part of their income in physical capital which is rented and used by the firms in the next period. They invest another part of their income to accumulate knowledge. When old, they consume the returns on their savings and die. At each date firms produce a single commodity under constant returns to scale technology. This commodity can either be consumed or accumulated as capital for future production. Capital is perfectly mobile across regions while labor is immobile.

\subsection{Preferences}

For a young household of region $i$, preferences are represented by the following utility function:

$$
\ln \left(c_{i, t}-\gamma a_{i, t}\right)+\beta \ln \left(d_{i, t+1}\right)+\lambda \ln \left(e_{i, t}\right) \quad i=A, B,
$$

where $c_{i, t}$ represents youth-age consumption, $a_{i, t}$ represents consumption habits, $d_{i, t+1}$ old-age consumption and $e_{i, t}$ spending on knowledge. The parameter $\gamma \in(0,1)$ stands for the influence of habits on preferences and $\lambda>0$ is the parameter governing the taste for spending revenue on education. The parameter $\beta>0$ is the discount factor. The stock of habits is built from the consumption of the previous generations (see de la Croix (2001) and de la Croix and Michel (2002)):

$$
a_{i, t}=c_{i, t-1} .
$$

Thus it is as though children became accustomed to a certain consumption level when they are still living with their parents.

In equation (1) we assume that the depreciation rate (or forgetting rate) of consumption habits is so high that old persons are no longer affected by them. This simplifying assumption proxies the idea that aspirations are less important for older persons. This is supported by the empirical observation that reported satisfaction levels in happiness surveys increases with age. Old households put less weight on comparisons to evaluate their welfare (see e.g. Clark et al.). The term $\lambda \ln \left(e_{i, t}\right)$ represents "joy-of-giving" altruism: providing education resources to their children makes parents happy.

\subsection{Technology}

Production is made through a Cobb-Douglas constant returns to scale technology:

$$
Y_{i, t}=A_{i, t} K_{i, t}^{\alpha} N_{i, t}^{1-\alpha},
$$


where $Y_{i, t}$ is the output of region $i$ at time $t, K_{i, t}$ is physical capital, $N_{i, t}$ is the labor input, and $A_{i, t}$ is the level of technology. Physical capital is assumed to be fully depreciated after one period. Technology depends on knowledge $h_{i, t}$ :

$$
A_{i, t}=A h_{i, t}^{\mu} .
$$

The parameter $\mu$ represents the elasticity of total factor productivity to knowledge and $A$ is a scale parameter. We assume that the total returns to reproducible inputs are decreasing, i.e., $\mu+\alpha<1$, to stay within the framework of neo-classical growth. Our interest is to study centrifugal forces that do not rely on the endogenous growth mechanism. Rewriting the production function in per capita terms, we have:

$$
y_{i, t}=A h_{i, t}^{\mu} k_{i, t}^{\alpha} \quad \text { with } \quad y_{i, t}=\frac{Y_{i, t}}{N_{i, t}}, \quad k_{i, t}=\frac{K_{i, t}}{N_{i, t}} .
$$

Knowledge is the engine of technical progress. We assume for simplicity that knowledge depends linearly on the amount of goods invested in it:

$$
h_{i, t+1}=\psi e_{i, t},
$$

where $e_{i, t}$ represents the amount of goods devoted to education and $\psi$ is a technological parameter, that we normalize to one, without loss of generality: $\psi=1$. Through consumption of the education commodity, each generation invests a part of its income in regional knowledge.

\subsection{Optimal Behaviors}

The regional representative consumer maximizes (1) subject to:

$$
\begin{aligned}
c_{i, t}+s_{i, t}+e_{i, t} & =w_{i, t}, \\
d_{i, t+1} & =R_{i, t+1} s_{i, t} .
\end{aligned}
$$

Savings are denoted $s_{i, t}$; he real wage is $w_{i, t}$ and the interest factor is $R_{i, t+1}$.

The first order conditions yield:

$$
\begin{aligned}
& e_{i, t}=\frac{\lambda}{1+\delta}\left(w_{i, t}-\gamma a_{i, t}\right), \\
& c_{i, t}=\frac{1}{1+\delta}\left(w_{i, t}+\gamma \delta a_{i, t}\right), \\
& s_{i, t}=\frac{\beta}{1+\delta}\left(w_{i, t}-\gamma a_{i, t}\right),
\end{aligned}
$$

where $\delta=\beta+\lambda$. Equations (5)-(7) depict an essential feature of the model. When past consumption $a_{i, t}$ is high, a larger share of income is devoted to current consumption, and a lower share to investment in knowledge and physical capital. Moreover, savings are proportional to education spending: 


$$
s_{i, t}=\frac{\beta}{\lambda} e_{i, t} .
$$

The regional representative firm maximizes profits subject to (3). Marginal productivities are thus equal to factor prices:

$$
\begin{aligned}
& R_{i, t}=A \alpha k_{i, t}^{\alpha-1} h_{i, t}^{\mu}, \\
& w_{i, t}=A(1-\alpha) h_{i, t}^{\mu} k_{i, t}^{\alpha} .
\end{aligned}
$$

\subsection{Equilibrium}

At equilibrium, the interest factor is identical in both regions since capital is perfectly mobile:

$$
R_{A, t}=R_{B, t}=R_{t} .
$$

The total stock of capital is built from the savings of the young generation:

$$
K_{t+1}=K_{A, t+1}+K_{B, t+1}=N_{A, t} s_{A, t}+N_{B, t} s_{B, t} .
$$

Given initial conditions $\left\{h_{i, 0}, a_{i, 0}, k_{i, 0}\right\}_{i=A, B}$ satisfying

$$
h_{A, 0}^{\frac{\mu}{1-\alpha}} k_{B, 0}=h_{B, 0}^{\frac{\mu}{1-\alpha}} k_{A, 0}, \text { and } k_{A, 0}+k_{B, 0}=\frac{\beta}{\lambda}\left(h_{A, 0}+h_{B, 0}\right)
$$

a competitive equilibrium can be characterized by a path $\left\{h_{i, t}, a_{i, t}, k_{i, t}\right\}_{i=A, B ; t>0}$ such that the following equations hold:

$$
\begin{aligned}
h_{i, t} & =\frac{\lambda}{1+\delta}\left[(1-\alpha) A h_{i, t-1}^{\mu} k_{i, t-1}^{\alpha}-\gamma a_{i, t-1}\right], \\
a_{i, t} & =\frac{1}{1+\delta}\left[(1-\alpha) A h_{i, t-1}^{\mu} k_{i, t-1}^{\alpha}+\gamma \delta a_{i, t-1}\right], \\
k_{A, t}+k_{B, t} & =\frac{\beta}{\lambda}\left(h_{A, t}+h_{B, t}\right), \\
h_{A, t}^{\frac{\mu}{1-\alpha}} k_{B, t} & =h_{B, t}^{\frac{\mu}{1-\alpha}} k_{A, t} .
\end{aligned}
$$

Equation (14) describes the accumulation of knowledge using equations (4), (5), and (10). Equation (15) gives the stock of habits as a function of past consumption through (2), (6), and (10). Equation (16) equalizes savings and investment (assuming constant population $N_{i, t}=1$ ), and is derived from (4), (8) and (12); it reflects the fact that savings are proportional to spending on knowledge. Equation (17) flows from the perfect capital mobility assumption, and is derived from equations (9) and (11).

Such an equilibrium exists provided that income $w_{i, t}$ is larger than the minimal desired consumption $\gamma a_{i, t}$, i.e.

$$
(1-\alpha) A h_{i, t}^{\mu} k_{i, t}^{\alpha}>\gamma a_{i, t} \quad \forall t>0 .
$$


Clearly, if it exists, it is unique.

\section{Regional Dynamics with Consumption Habits}

We now derive some theoretical properties of the equilibrium that we use to characterize regional development patterns. Numerical examples will then be provided.

\subsection{Steady State and Dynamics}

Proposition 1 [Steady state] The dynamic system described by equations (14)-(17) allows for a unique non-trivial steady state. This steady state is symmetric:

$$
\begin{aligned}
& \bar{h}_{A}=\bar{h}_{B}=\bar{h}=\left(\frac{A(1-\alpha)(1-\gamma) \lambda^{1-\alpha} \beta^{\alpha}}{1+(\beta+\lambda)(1-\gamma)}\right)^{\frac{1}{1-\mu-\alpha}}, \\
& \bar{k}_{A}=\bar{k}_{B}=\bar{k}=\frac{\beta}{\lambda} \bar{h} \\
& \bar{a}_{A}=\bar{a}_{B}=\bar{a}=\frac{\bar{h}}{\lambda(1-\gamma)} .
\end{aligned}
$$

Proof: see Appendix A.

From these expressions, we see that the stock of knowledge is decreasing in parameter $\gamma$, which measures the importance of habits in household preferences. Since $\bar{k}$ is also decreasing in $\gamma$, output per capita is decreasing in $\gamma$ as well. Substituting the values of $\bar{k}$ and $\bar{h}$ into (9), we obtain the steady state value of the interest rate:

$$
\bar{R}=\frac{\alpha}{\beta(1-\alpha)} \frac{1+(\beta+\lambda)(1-\gamma)}{1-\gamma}
$$

$\bar{R}$ is increasing in $\gamma$ : the larger the weight of habits, the smaller the investment. Logically, an increase in $\gamma$ makes capital more scarce and expensive.

Looking at the local stability of the steady state, we get the following result:

Proposition 2 [Hopf bifurcation] There exists a value $\gamma_{1} \in(0,1)$ such that at $\gamma=\gamma_{1}$ the steady state (19) is non-hyperbolic, the eigenvalues of the Jacobian of the linearized system have moduli less than unity with the exception of a conjugate pair of complex eigenvalues of modulus $1,\left\{\ell_{\gamma}, \bar{\ell}_{\gamma}\right\}$. This pair of eigenvalues also satisfies $\ell_{\gamma}^{3} \neq 0, \ell_{\gamma}^{4} \neq 0$ and $\partial \ell_{\gamma} / \partial_{\gamma}>0$ at $\gamma=\gamma_{1} \cdot \gamma_{1}$ is given by the following expression:

$$
\gamma_{1}=\frac{(1+\delta)(1+\alpha+\mu)-\sqrt{(1+\delta)^{2}(1+\alpha+\mu)^{2}-4 \delta(1+\delta)(\alpha+\mu)}}{2 \delta(\alpha+\mu)} .
$$




\section{Proof: See Appendix B.}

Proposition 2 establishes that a Hopf bifurcation occurs when the weight attached to past consumption becomes large enough. The presence of a Hopf bifurcation determines crucially the economic properties of the model. Indeed, dynamics around the bifurcation point are oscillatory; they converge to the steady state if the parameter $\gamma$ lies on the low side of the critical point, accounting for non-monotonic convergence behavior. Moreover, bifurcation theory shows that there is an invariant manifold diffeomorphic to a circle on one side of the bifurcation point (Ruelle, 1989). If this manifold is on the stable side, it is repelling and determines a basin of attraction of the steady state. Hence two worlds with almost identical initial conditions but lying on different sides of the manifold might display dramatically different growth patterns: the one starting inside the cycle will be attracted to the steady state, and its regions will finally converge; the other will be repelled from the steady state, and regional disparities will not vanish. If the manifold is on the unstable side, it is then attracting, and economies that do not converge to the steady state will fluctuate forever.

The Hopf bifurcation argument is only valid in a neighborhood of the steady state and of the parameter critical value. We can however prove a more general stability result for any value of $\gamma$ in its definition interval:

Proposition 3 [Local dynamics] The steady state (19) is locally stable for all $\gamma \in\left(0, \gamma_{1}\right)$. There exists $\underline{\gamma} \in\left(0, \gamma_{1}\right)$ for which local dynamics are oscillatory if $\gamma \in\left(\underline{\gamma}, \gamma_{1}\right)$.

Proof: see Appendix C.

Hence, the interval $\left(0, \gamma_{1}\right)$ can be divided into two sub-intervals. If, $\gamma \in(0, \gamma)$, then the system converges monotonically. If, $\gamma \in\left(\underline{\gamma}, \gamma_{1}\right)$, convergence is oscillatory.

\subsection{Numerical Example}

In this two-region economy four forces are at work: diminishing returns on physical capital, diminishing returns on knowledge, mobility of physical capital across regions and consumption habits. The first three are convergence forces and the fourth is a divergence force. We simulate the model to illustrate how these forces interact as a function of the initial knowledge and of the parameter $\gamma$. Figure 4 displays regional $\mathrm{GDP}^{5}$ in four cases. In all examples, the parameter values are: $\alpha=1 / 3, \beta=1 / 2, \lambda=1 / 2, \mu=1 / 2, A=10$. The corresponding Hopf bifurcation

5 We have also drawn the figures with regional GNP, which equals in our case $y_{i, t}+R_{t}\left(s_{i, t-1}--K_{i, t}\right)$. The income from abroad is small compared to GDP, and the dynamics are the same. 
(i): Alternating primacy

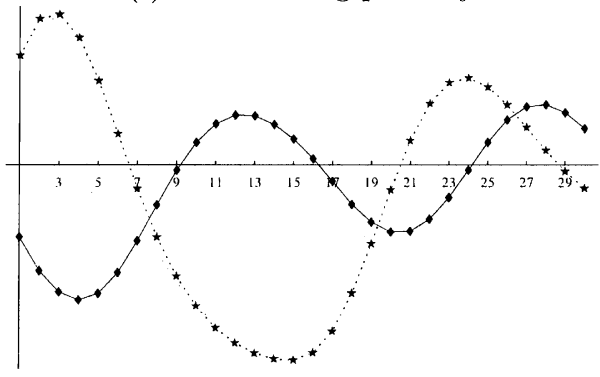

(iii): Synchronized waves

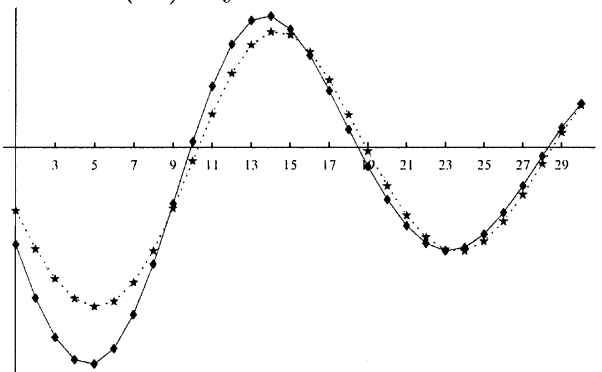

(ii): Irreversible decline

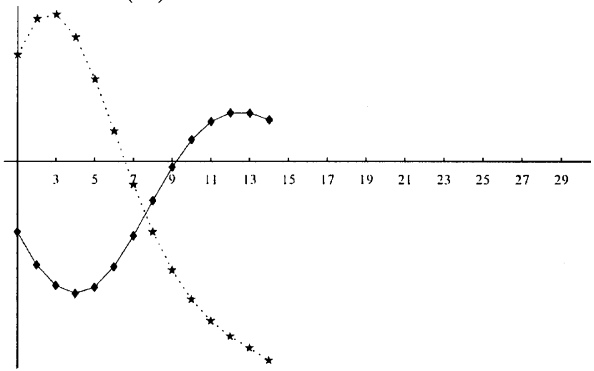

(iv): Monotonic convergence

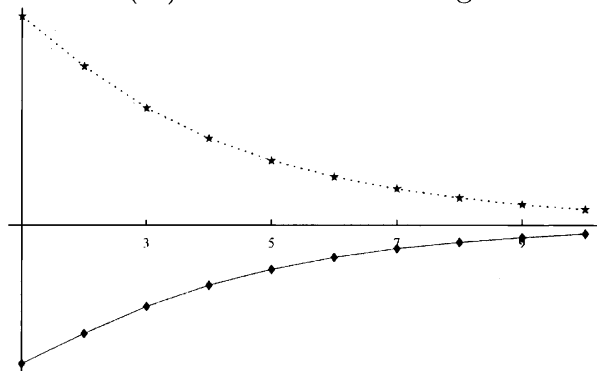

Figure 4. Numerical examples: $Y_{A, t}$ (dotted line), $Y_{B, t}$ (solid line).

value, $\gamma_{1}$, is 0.63795 . In our first three examples, we have chosen a value for the weight of habits close enough to the bifurcation value: $\gamma=0.62$; a large value of $\gamma$ is consistent with the weak link found in the literature between income and reported satisfaction by households (de la Croix 1998). The associated eigenvalues are complex: $\ell_{1,2}=0.911579 \pm 0.327386 i$ and $\ell_{3,4}=0.835921 \pm 0.381547 i$. In our last example, we have chosen a small value for $\gamma, 0.05$.

Initial conditions are $a_{A, 0}=a_{B, 0}=\bar{a} ; k_{A, 0}$ and $k_{B, 0}$ are set so that the interest rate $R_{0}$ equals its long-term value. We then consider three different sets of initial conditions for knowledge. In Panel $(i)$, region A is endowed with a level of knowledge above its steady state value, while region $\mathrm{B}$ starts at the same distance from the steady state but below it: $h_{A, 0}=\bar{h} \times 1.751, h_{B, 0}=\bar{h} / 1.751$. Both regions have thus different stocks of knowledge but equal consumption habits. Due to the presence of diminishing returns on physical capital and knowledge, the poorer region is expected to grow faster during the first few periods. In fact, output decreases initially in the poor region because its initial habits are burdensome. In other words, consumption habits become an obstacle to the accumulation of knowledge. In particular, future returns on physical capital are dragged down by low level of productivity, and the poor region is unable to attract foreign capital. Their relative positions start changing when the poor region's consumption goes low enough, allowing a larger share of revenue to be devoted to investment in knowledge. As a result, the poor region grows faster and overtakes the rich region at $t=8$. Then, habits become hard 
to bear again and the region declines from $t=13$. As time goes by, the waves synchronize due to the three convergence forces while their amplitude diminishes.

In Panel (ii), the distance between initial knowledge levels and the steady state is in-finitesimally longer than in Panel $(i): h_{A, 0}=\bar{h} \times 1.752, h_{B, 0}=\bar{h} / 1.752$. This illustrates the case when initial conditions do not lie within the basin of attraction defined by the repelling manifold. The local stability results obtained in the previous section do not apply and the economies do not converge. After $t=14$ condition (18) is violated for the initially rich region, wages are insufficient to fulfill consumption habits, and its decline is irreversible.

In Panel (iii), both regions have initial knowledge below the steady state, with a higher level in region A: $h_{A, 0}=\bar{h} \times 0.8, h_{B, 0}=\bar{h} \times 0.7$ (the exercise could also have been carried out with two regions above steady state). Alternating primacy occurs again but waves are synchronized from the beginning. These waves are still generated by the large weight of consumption habits. The similarity of initial physical capital, knowledge and habit stocks implies the same behavior of both economies over time. The mechanism explained for Panel $(i)$ applies, the waves become less and less ample and eventually convergence takes place.

In Panel (iv), initial conditions are the same as in Panel $(i)$, but remember that the parameter $\gamma$ is much lower. Convergence forces always dominate habits and dynamics are monotonic. Our model thus behaves like a traditional neo-classical growth model for low values of $\gamma$.

\section{The Role of Capital Mobility}

In the previous sections, we have shown that diminishing returns and perfect capital mobility do not guarantee fast convergence. This result contrasts with what happens in the two-country one-sector model with two factors (Buiter, 1981). To assess the specific role of capital mobility, we examine the model when capital is immobile. We expect a priori convergence to be even slower. With no capital mobility, the system (14)-(17) becomes:

$$
\begin{aligned}
& h_{i, t}=\frac{\lambda}{1+\delta}\left((1-\alpha) A h_{i, t-1}^{\mu} k_{i, t-1}^{\alpha}-\gamma a_{i, t-1}\right), \\
& a_{i, t}=\frac{1}{1+\delta}\left((1-\alpha) A h_{i, t-1}^{\mu} k_{i, t-1}^{\alpha}+\gamma \delta a_{i, t-1}\right), \\
& k_{i, t}=s_{i, t-1}=\frac{\beta}{\lambda} h_{i, t}, \quad i=A, B .
\end{aligned}
$$

Given initial conditions $\left\{h_{i, 0}, a_{i, 0}, k_{i, 0}\right\}_{i=A, B}$ satisfying $k_{i, 0}=\beta / \lambda h_{i, 0}$ for $I=A, B$, a competitive equilibrium can be characterized by a path $\left\{h_{i, t}, a_{i, t}, k_{i, t}\right\}_{i=A, B ; t>0}$ such that equations (20)-(22) hold. The analysis of this system is much simpler because we can study each region separately. We can show that there is a unique nontrivial steady state, which is the same as the one with perfect capital mobility. It turns out that there is also a Hopf bifurcation for the parameter $\gamma$. The value of the bifurcation point is $\gamma_{1}$, the same as in the case of perfect capital mobility. 
Proposition 4 [No capital mobility] With no capital mobility, the steady state is locally stable for $\gamma \in\left[0, \gamma_{1}\right)$. For $\gamma$ in a neighborhood on the left of $\gamma_{1}$, the speed of convergence is slower than with perfect mobility of capital.

\section{Proof: See Appendix D.}

Proposition 4 proves that the convergence speed is higher when capital is perfectly mobile across regions. A similar result obtains in two-country models when a third immobile production factor such as land is introduced. Mountford (1996) shows that for reasonable values of the elasticity of substitution between land and capital, convergence is faster when capital is mobile. Moreover capital mobility has other implications which can be high-lighted numerically: it enlarges the basin of attraction of the steady state and promotes regional synchronization. Let us detail these two points in turn.

In the left panel of Figure 5 we take the example of one region without mobility of capital with the same parameters values as in panel A of Figure 4. In bold, we plot the invariant manifold in the space $\{a, h\}$, homeomorphic to a circle, which surrounds the stable steady state. If the initial conditions of one region lie inside the circle, the region converges to the steady state. If they lie outside, the economy diverges and condition (18) is violated at some point in time. The solid line reports the trajectory of the same region when there is capital mobility (from the example in panel A of Figure 4). We observe that it converges to the steady state, although it started outside the circle; it implies that, if capital was prevented from flowing from one region to the other, the trajectory would have diverged. As a result, a region can start from a more distant point from the steady state with perfect capital mobility. For example, households can afford higher consumption habits when capital is mobile since their region has the possibility of attracting foreign physical capital.

The right panel of Figure 5 depicts the dynamics of regional outputs with the same parameters, but starting closer to the steady state to ensure convergence: $h_{A, 0}=\bar{h} \times 1.5, h_{B, 0}=\bar{h} / 1.5$. We see that the synchronization of regional outputs has disappeared. We can conclude that capital mobility is the force of synchronization.
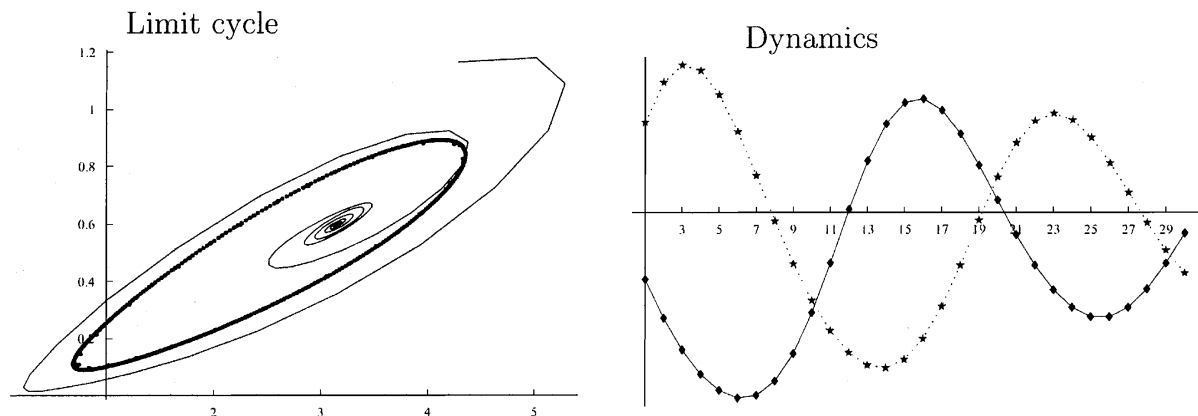

Figure 5. Numerical example without capital mobility. 


\section{Case Study: Belgium - The Netherlands}

In contrast to the literature which relies on exogenous shocks to explain leapfrogging, our framework stresses the role of initial conditions. To better understand their role in shaping the future, we have used the model to simulate the Belgium (B)-Netherlands (NL) relative GDP per capita between 1500 and 2000. We take the same parameter values as in Section 4.2 and assume that one period in the model is equivalent to a third of a century.

We set the initial level of knowledge for Belgium, $h_{B, 0}$, and the initial level of habits for the Netherlands, $a_{N}$ L,, at their steady state values. The two other initial conditions, $\mathrm{h}_{\mathrm{N}, 0}$ and $\mathrm{a}_{\mathrm{B}, 0}$, are chosen to match the relative GDP per capita in 1500 and 1600 as provided by Maddison (1995), see Table 2. The initial stocks of capital $\mathrm{k}_{\mathrm{i}, 0}$ are related to the initial stocks of knowledge through conditions (13). The system (14)-(17) is then solve for $t$ going from 1 to 15. Figure 6 compares the simulated with the actual series. The model predicts well the drop in Belgium's relative GDP from 1600 to 1700; the low point seems to be fairly well captured, although we do not have observations between 1700 and 1800 to precisely identify this point. In the model economy, Belgium overtakes the Netherlands in 1866, while this actually takes place in 1880 . Then, Belgium stays above the Netherlands in the model economy, while it falls below it around 1940 in the series.

In the literature on the history of the Netherlands, the expansion of the 16th century is closely related to investment in knowledge, while the decline of the 18th century is associated to a lack of investment to remain the leader. De Vries and Van Der Woude (1997) note the substantial investment in "human capital" realized by the Netherlands: "The occupational structure of this economy was such that a large fraction of the labor force required formal education and occupational training, both of which required investment, at least in terms of foregone income. (...) The early rise of basic literacy rates, the large proportion of the labor force trained in formal apprenticeships, and the large proportion, by the standards of that time,

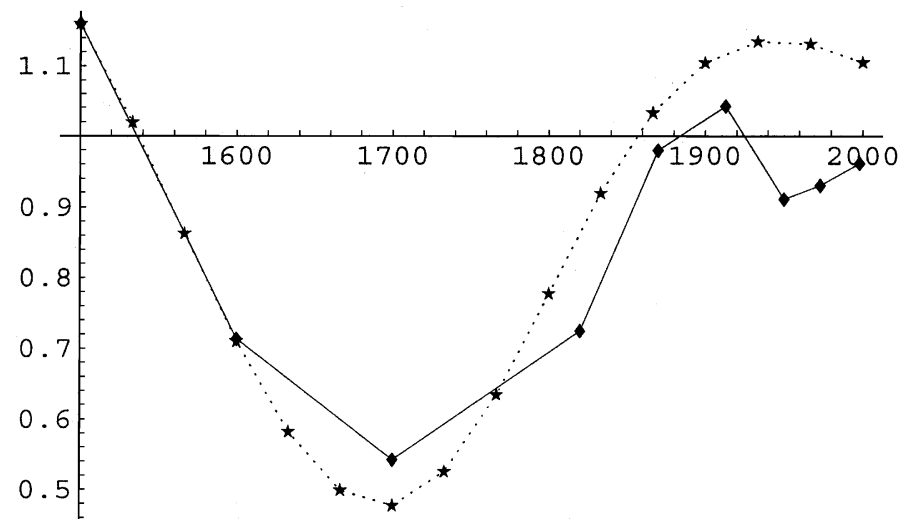

Figure 6. Simulated (dots) versus Actual (solid) Relative GDP per capita-B/NL. 
enrolled in universities and illustrious schools, all reflect a substantial investment in human capital formation"' (p. 694-695).

As for the decline, Burke (1974) cites the Dutch historian Lieuwe van Aitzema in 1652: "Dutch regents were not merchants. They did not take risks on the sea, but derived their incomes from houses, lands and securities, and so allowed the sea to be lost". Burke concludes that contemporaries remarked a very important shift in the style of life of the elites in the course of the 17th century. The shift was from sea to land, from work to play, from thrift to conspicuous consumption. This view is supported by data from Dijk and Roorda (1971) on the occupation of Dutch regents, presented in Table 1.

These numbers provide evidence about the shift in occupations of Dutch regents. From 1618 to 1650 , only $33 \%$ of regents were without occupation (and thus entiers); this number rose to $73 \%$ over the years $1702-1748$. The same trend is observed in the percentage of regents having a country house, stressing that more resources were put into consumption goods. Notice also that the trend in both indicators tend to revert during the last period considered.

Let us now look at the initial conditions responsible for these long waves of decline and rebirth. They are presented in Table 2. As we said above, we set the relative initial consumption habits and knowledge to match the first two observations (1500 and 1600); initial consumption habits are higher in Belgium than in the Netherlands by $28 \%$ and initial knowledge by $21 \%$. These levels are consistent with high urbanization rates in Belgium before 1500. Urbanization rates are indeed correlated with education and knowledge, since schools and universities were essentially located in cities, and with high consumption habits, since luxury goods were available in cities through trade. Figures in Bairoch et al. (1988) show that before 1500 Belgium had the highest urbanization rate in Europe (it is also the highest urbanization rate ever observed in the world over the period 1000-1800) and far above the Dutch rate. In summary, the main lesson that can be drawn from Table 2 is that consumption

Table 1. Habits of Dutch regents.

\begin{tabular}{lll}
\hline Period & Regents (\%) without occupation & Regents (\%) with country house \\
\hline $1618-1650$ & 33 & 19 \\
$1650-1672$ & 66 & 41 \\
$1672-1702$ & 55 & 30 \\
$1702-48$ & 73 & 81 \\
$1748-1787$ & 61 & 67 \\
\hline
\end{tabular}

Table 2. Initial conditions for Belgium and the Netherlands in 1500.

\begin{tabular}{llll}
\hline year 1500 & Belgium $(\mathrm{B})$ & The Netherlands $(\mathrm{NL})$ & $\mathrm{B} / \mathrm{NL}$ \\
\hline Knowledge $\left(h_{\mathrm{i}, 0}\right)$ & 0.598 & 0.491 & 1.219 \\
Habit stock $\left(a_{\mathrm{i}, 0}\right)$ & 4.033 & 3.147 & 1.281 \\
GDP per capita* & 875 & 754 & 1.16 \\
\hline
\end{tabular}

*Source: Maddison (1995). 
habits in Belgium exceed the Dutch level by a larger extent than knowledge, and this is able to generate the relative decline of Belgium after 1500 .

As a last check to evaluate the likelihood of the simulation we can look at the generated interest rate and wonder where it is reasonable. It starts at $4 \%$ per annum in 1500 , increases to reach $4.4 \%$ before 1700 and declined monotonically afterwards, to reach $3.8 \%$ in 2000 . These numbers are reasonable compared to the level of the interest rate in Epstein (2000) who reports a level slightly above 4\% for Flanders in 1551-1560 (cost of private capital, p. 62). The simulation also shows that the model does not generate wild fluctuations in the interest rate, although it accounts for large changes in regional outputs.

\section{Conclusion}

The decline of civilizations has often been associated with excessive consumption, to the detriment of investment and education. Wealth breeds first more wealth, and then decline, according to Kindleberger (1996). We have formalized this idea in a two-region model: when one region leads, its inhabitants develop consumption habits incompatible with the necessary investment in knowledge to remain the leader. This opens the possibility for the other region to catch up and gain economic primacy.

We have learned from the theoretical model that differences across regions that are similar in their characteristics may persist even when physical capital flows from rich regions to poor ones. Perfect capital mobility helps but does not guarantee a fast and monotonic convergence process.

We have exploited the economic implications of the Hopf bifurcation to show that different patterns of regional development may emerge as a function of initial conditions. In particular, regional dynamics can display alternating primacy if the initial dispersion of knowledge is high and habit formation is strong. Irreversible decline happens when rich regions develop unsustainable habits. When the weight of habits is low, our model behaves like the traditional neo-classical growth model and monotonic convergence prevails.

In contrast to the models of economic geography where agglomeration forces often imply catastrophic outcomes, our model based on consumption habits does not necessarily predict the disappearance of certain activities within regions. Moreover, poor regions can overtake rich ones without the need for an exogenous shock; this is an endogenous outcome of the model, based on the dynamics of consumption patterns. Our aim was not to claim that exogenous shocks were unimportant to account for development dynamics but to stress that they are not necessary to account for reversals of leadership.

The key assumption of the model is that the propensity to consume depends on the standard-of-living one has experienced as a child. Reversals of fortune arise as a consequence of habit formation, which shapes preferences towards consumption versus investment. An alternative way to model changes in preferences is followed by Galor and Moav (2002): they use evolutionary theory to explain how a long 
period of struggle for survival during the Malthusian stagnation increased the weight attached to the quality of children in the population, which in turn fostered the take-off process. However, when only a few centuries are concerned, inheritance of cultural habits is stronger than inheritance of genes.

Our model shares common elements with the Shumpeterian view of economic change, as developed in the recent book by Mokyr (2002). In his chapter 6, Mokyr mentions a "law" according to which the leader always looses its primacy and never gains it back. This is explained by the formation of groups opposing innovation. Even if technological innovation enhances growth, it entails losers and winners, and some groups always oppose to it. Conservatism is not the same idea as habit formation, but it is close to it. Contrary to Mokyr's view, our dynamic analysis shows that a decline is not necessarily irreversible, and rebirth may arise if the period of poverty cleans up the forces working against growth. ${ }^{6}$

Two extensions of the present framework can be considered for future research: first, the interactions between regions are not limited to capital movements or trade; knowledge spillovers can play an important role. Second, cross-border envy effects can be easily modeled in our set-up. We wonder whether these additional interactions between regions will foster or hamper convergence, and whether long waves can be shortened or lengthened.

Finally, Burke (1974) inspires another interesting extension. According to him, the continued immigration in Amsterdam was the main reason for the survival of entrepreneurship attitudes in this city. Hence, the decline can be postponed if the leader is able to attract skilled people from abroad. A two-region model with some mobility of labor can be a natural set-up to study this issue.

\section{Appendix A}

\section{A. Proof of Proposition 1.}

The steady state is computed from equations (14)-(17). The first step consists in expressing $h_{i}$ only in terms of $a_{i}$, using (14)-(15):

$$
h_{i}=\lambda(1-\gamma) a_{i}, \quad i=A, B
$$

Using (23) in (17) yields:

$$
\frac{a_{B}}{a_{A}}=\left(\frac{k_{B}}{k_{A}}\right)^{\frac{1-\alpha}{\mu}}
$$

6 This property comes from our two region framework; when the leader declines it is the old leading region which takes the lead again. This is not necessarily true in an n-region model. 
From (15) we obtain:

$$
\frac{a_{B}}{a_{A}}=\left(\frac{k_{B}}{k_{A}}\right)^{\frac{\alpha}{1-\mu}}
$$

Equations (24) and (25) imply $a_{A}=a_{B}=\beta$, and $k_{A}=k_{B}=\bar{k}$ which in turn imply $h_{A}=h_{B}=\bar{h}$. Thus the steady state is proved to be symmetric. Once symmetry is taken into account, the steady state $(\bar{k}, \bar{a}, \bar{h})$, as expressed in Proposition 1 , is the only solution to equations (14)-(17). Q.E.D.

\section{Appendix B}

\section{B. Proof of Proposition 2.}

Let us express the dynamic system with seven equations and seven unknowns instead of using the redundant free system of the main text made up of four equations and four unknowns. It turns out that the Jacobian of the system with seven variables can be worked out more easily. For the sake of simplicity, we denote $\phi=\frac{1-\alpha}{\alpha}$ Then, the dynamic system is as follows:

$$
\begin{aligned}
& h_{A, t+1}=\frac{\lambda}{1+\delta}\left(\phi R_{t} k_{A, t}-\gamma a_{A, t}\right) \\
& a_{A, t+1}=\frac{1}{1+\delta}\left(\phi R_{t} k_{A, t}+\gamma \delta a_{A, t}\right) \\
& k_{A, t+1}=\frac{\beta}{1+\delta} \\
& \frac{\left(\phi R_{t}\left(k_{A, t}+k_{B, t}\right)-\gamma\left(a_{A, t}+a_{B, t}\right)\right)\left(\phi R_{t} k_{A, t}-\gamma a_{A, t}\right)^{\frac{\mu}{1-\alpha}}}{\left(\phi R_{t} k_{A, t}-\gamma a_{A, t}\right)^{\frac{\mu}{1-\alpha}}+\left(\phi R_{t} k_{B, t}-\gamma a_{B, t}\right)^{\frac{\mu}{1-\alpha}}} \\
& h_{B, t+1}=\frac{\lambda}{1+\delta}\left(\phi R_{t} k_{B, t}-\gamma a_{B, t}\right) \\
& a_{B, t+1}=\frac{1}{1+\delta}\left(\phi R_{t} k_{B, t}+\gamma \delta a_{B, t}\right) \\
& k_{B, t+1}=\frac{\beta}{1+\delta} \\
& \frac{\left(\phi R_{t}\left(k_{A, t}+k_{B, t}\right)-\gamma\left(a_{A, t}+a_{B, t}\right)\right)\left(\phi R_{t} k_{B, t}-\gamma a_{B, t}\right)^{\frac{\mu}{1-\alpha}}}{\left(\phi R_{t} k_{A, t}-\gamma a_{A, t}\right)^{\frac{\mu}{1-\alpha}}+\left(\phi R_{t} k_{B, t}-\gamma a_{B, t}\right)^{\frac{\mu}{1-\alpha}}} \\
& R_{t+1}=A \alpha\left(\frac{\lambda}{1+\delta}\right)^{\mu}\left(\frac{\beta}{1+\delta}\right)^{\alpha-1} \\
& \left(\frac{\left(\phi R_{t} k_{A, t}-\gamma a_{A, t}\right)^{\frac{\mu}{1-\alpha}}+\left(\phi R_{t} k_{B, t}-\gamma a_{B, t}\right)^{\frac{\mu}{1-\alpha}}}{\phi R_{t}\left(k_{A, t}+k_{B, t}\right)-\gamma\left(a_{A, t}+a_{B, t}\right)}\right)^{1-\alpha}
\end{aligned}
$$

The linearized system is: 


$$
\left[\begin{array}{c}
h_{A, t+1}-\bar{h} \\
a_{A, t+1}-\bar{a} \\
k_{A, t+1}-\bar{K} \\
h_{B, t+1}-\bar{h} \\
a_{B, t+1}-\bar{a} \\
k_{B, t+1}-\bar{k} \\
R_{t+1}-\bar{R}
\end{array}\right]=J .\left[\begin{array}{c}
h_{A, t}-\bar{h} \\
a_{A, t}-\bar{a} \\
k_{A, t}-\bar{K} \\
h_{B, t}-\bar{h} \\
a_{B, t}-\bar{a} \\
k_{B, t}-\bar{k} \\
R_{t}-\bar{R}
\end{array}\right]+O(\varepsilon)
$$

with

$$
J=\left[\begin{array}{ccccccc}
0 & \frac{-\gamma \lambda}{1+\delta} & \frac{\lambda \phi \bar{R}}{1+\delta} & 0 & 0 & 0 & \frac{\lambda \phi}{1+\delta} \bar{k} \\
0 & \frac{\gamma \delta}{1+\delta} & \frac{\phi \bar{R}}{1+\delta} & 0 & 0 & 0 & \frac{\phi}{1+\delta} \bar{k} \\
0 & \frac{-\gamma \beta}{2(1+\delta)} \frac{1-\alpha+\mu}{1-\alpha} & \frac{\phi \beta}{2(1+\delta)} \frac{1-\alpha+\mu}{1-\alpha} \bar{R} & 0 & \frac{-\gamma \beta}{2(1+\delta)} \frac{1-\alpha-\mu}{1-\alpha} & \frac{\phi \beta}{2(1+\delta)} \frac{1-\alpha-\mu}{1-\alpha} \bar{R} & \frac{\beta \phi}{1+\delta} \bar{k} \\
0 & 0 & 0 & 0 & \frac{-\gamma \lambda}{1+\delta} & \frac{\lambda}{1+\delta} \phi \bar{R} & \frac{\lambda \phi}{1+\delta} \bar{k} \\
0 & 0 & 0 & 0 & \frac{\gamma \delta}{1+\delta} & \frac{1}{1+\delta} \phi \bar{R} & \frac{\phi}{1+\delta} \bar{k} \\
0 & \frac{-\gamma \beta}{2(1+\delta)} \frac{1-\alpha-\mu}{1-\alpha} & \frac{\phi \beta}{2(1+\delta)} \frac{1-\alpha-\mu}{1-\alpha} \bar{R} & 0 & \frac{-\gamma \beta}{2(1+\delta)} \frac{1-\alpha+\mu}{1-\alpha} & \frac{\phi \beta}{2(1+\delta)} \frac{1-\alpha+\mu}{1-\alpha} \bar{R} & \frac{\beta \phi}{1+\delta} \bar{k} \\
0 & R_{a}^{\prime} & R_{k}^{\prime} & 0 & R_{a}^{\prime} & R_{k}^{\prime} & R_{R}^{\prime}
\end{array}\right]
$$

where $\bar{R}$ and $\bar{k}$ stand for the steady state values of the interest rate and physical capital, and

$$
\begin{aligned}
R_{a}^{\prime} & =\frac{\gamma(1-\mu-\alpha)}{2 \phi \bar{k}} H(\gamma), \\
R_{k}^{\prime} & =\frac{\bar{R}(\mu+\alpha-1)}{2 \bar{k}} H(\gamma), \\
R_{R}^{\prime} & =(\mu+\alpha-1) H(\gamma), \\
\text { with } H(\gamma) & =\frac{1+\delta(1-\gamma)}{(1+\delta)(1-\gamma)} .
\end{aligned}
$$

Let us briefly describe the steps to compute the eigenvalues of $J$. Since the first and fourth columns of $|J-I I|$ contain only one element different from zero $(-l)$, we can apply the Laplace expansion twice. Next, we add the first column of the new determinant to the third and the second to the fourth. Then, we substract the third row to the first, and afterwards we add the fourth to the second. Thereafter, we multiply the third and fourth column by $-\frac{1}{2}$ and we add the result to the first and second column respectively. We multiply the first and the second row by $\frac{1}{2}$ and add the result to the third and the fourth row respectively. Multiplying the third row by $-\beta$ and adding it to the fourth row, we obtain:

$$
|\tilde{J}|=\left|\begin{array}{ccccc}
\frac{\gamma \delta}{1+\delta}-\ell & \frac{\phi}{1+\delta} \bar{R} & 0 & 0 & 0 \\
\frac{-\gamma \beta}{1+\delta} \frac{\mu}{1-\alpha} & \frac{\phi \beta}{1+\delta} \frac{\mu}{1-\alpha} \bar{R}-\ell & 0 & 0 & 0 \\
0 & 0 & \frac{\gamma \delta}{1+\delta}-\ell & \frac{\phi}{1+\delta} \bar{R} & \frac{\phi}{1+\delta} \bar{k} \\
0 & 0 & \beta(1-\gamma) & -\ell & 0 \\
0 & 0 & 2 R_{a}^{\prime} & 2 R_{k}^{\prime} & R_{R}^{\prime}-\ell
\end{array}\right| \ell^{2}
$$


Therefore, $|\tilde{J}|$ can be computed as:

$$
|\tilde{J}|=\ell^{2}\left|\begin{array}{ccc}
\frac{\gamma \delta}{1+\delta}-\ell & \frac{\phi}{1+\delta} \bar{R} & \frac{\phi}{1+\delta} \bar{k} \\
\beta(1-\gamma) & -\ell & 0 \\
2 R_{a}^{\prime} & 2 R_{k}^{\prime} & R_{R}^{\prime}-\ell
\end{array}\right| \begin{array}{cc}
\frac{\gamma \delta}{1+\delta}-\ell & \frac{\phi}{1+\delta} \bar{R} \\
-\frac{\gamma \beta}{1+\delta} \frac{\mu}{1-\alpha} & \frac{\phi \beta}{1+\delta} \frac{\mu}{1-\alpha} \bar{R}-\ell
\end{array} \mid
$$

The first determinant can be further developed:

$$
\begin{aligned}
\left|\begin{array}{ccc}
\frac{\gamma \delta}{1+\delta}-\ell & \frac{\phi}{1+\delta} \bar{R} & \frac{\phi}{1+\delta} \bar{k} \\
\beta(1-\gamma) & -\ell & 0 \\
2 R_{a}^{\prime} & 2 R_{k}^{\prime} & R_{R}^{\prime}-\ell
\end{array}\right| & =\frac{\phi \bar{k}}{1+\delta}\left|\begin{array}{cc}
\beta(1-\gamma) & -\ell \\
2 R_{a}^{\prime} & 2 R_{k}^{\prime}
\end{array}\right| \\
& +\left(R_{R}^{\prime}-\ell\right)\left|\begin{array}{cc}
\frac{\gamma \delta}{1+\delta}-\ell & \frac{\phi}{1+\delta} \bar{R} \\
\beta(1-\gamma) & -\ell
\end{array}\right| .
\end{aligned}
$$

After some computations, the following polynomial obtains:

$$
\ell^{2}-\ell\left(\frac{\gamma \delta}{1+\delta}+\frac{(\mu+\alpha)(1+\delta(1-\gamma))}{(1+\delta)(1-\gamma)}\right)+\gamma\left(\frac{(\mu+\alpha)(1+\delta(1-\gamma))}{(1+\delta)(1-\gamma)}\right)=0,
$$

whose roots, $l_{1,2}$ are:

$$
\begin{aligned}
& \ell_{1}=\frac{1}{2}\left(\frac{\gamma \delta}{1+\delta}+(\mu+\alpha) H(\gamma)-\sqrt{\left(\frac{\gamma \delta}{1+\delta}+(\mu+\alpha) H(\gamma)\right)^{2}-4 \gamma(\mu+\alpha) H(\gamma)}\right) \\
& \ell_{2}=\frac{1}{2}\left(\frac{\gamma \delta}{1+\delta}+(\mu+\alpha) H(\gamma)+\sqrt{\left(\frac{\gamma \delta}{1+\delta}+(\mu+\alpha) H(\gamma)\right)^{2}-4 \gamma(\mu+\alpha) H(\gamma)}\right) .
\end{aligned}
$$

The development of the second polynomial leads to the following couple of eigenvalues:

$$
\begin{aligned}
& \ell_{3}=\frac{1}{2}\left(\frac{\gamma \delta}{1+\delta}+\frac{\mu H(\gamma)}{1-\alpha}-\sqrt{\left.\left(\frac{\gamma \delta}{1+\delta}+\frac{\mu H(\gamma)}{1-\alpha}\right)^{2}-4 \frac{\gamma \mu H(\gamma)}{1-\alpha}\right)},\right. \\
& \ell_{4}=\frac{1}{2}\left(\frac{\gamma \delta}{1+\delta}+\frac{\mu H(\gamma)}{1-\alpha}+\sqrt{\left.\left(\frac{\gamma \delta}{1+\delta}+\frac{\mu H(\gamma)}{1-\alpha}\right)^{2}-4 \frac{\gamma \mu H(\gamma)}{1-\alpha}\right)} .\right.
\end{aligned}
$$

Following Ruelle (1989), a dynamic system undergoes a Hopf bifurcation if:

a) There exists a couple of complex eigenvalues depending on $\gamma$, such that

$$
\begin{aligned}
& \left|\ell_{\gamma}\right|=1 \\
& \ell_{\gamma}^{3} \neq 0 \\
& \ell_{\gamma}^{4} \neq 0
\end{aligned}
$$


b) This couple of complex eigenvalues verifies:

$$
\frac{\partial\left|\ell_{\gamma}\right|}{\partial \gamma}>0
$$

in the neighborhood of $\gamma_{1}$.

c) The other eigenvalues have modulus less than unity.

The condition a) is verified as follows:

We first compute the values of $\gamma$ for which complex eigenvalues have modulus

1. We exploit the fact that, if $l_{1,2}$ are complex conjugates, then

$$
\left|\ell_{1,2}\right|=\sqrt{\gamma(\mu+\alpha) H(\gamma)} \text {. }
$$

Similarly, if $l_{3,4}$ are complex conjugates, then

$$
\left|\ell_{3,4}\right|=\sqrt{\frac{\gamma \mu H(\gamma)}{1-\alpha}}
$$

Thus, the values of $\gamma$ solving $\left|l_{1,2}\right|=1$ are:

$$
\begin{aligned}
& \gamma_{1}=\frac{(1+\delta)(1+\alpha+\mu)-\sqrt{(1+\delta)^{2}(1+\alpha+\mu)^{2}-4 \delta(1+\delta)(\alpha+\mu)}}{2 \delta(\alpha+\mu)} \\
& \gamma_{2}=\frac{(1+\delta)(1+\alpha+\mu)+\sqrt{(1+\delta)^{2}(1+\alpha+\mu)^{2}-4 \delta(1+\delta)(\alpha+\mu)}}{2 \delta(\alpha+\mu)}
\end{aligned}
$$

The values of $\gamma$ solving $\left|l_{3,4}\right|=1$ are:

$$
\begin{aligned}
& \gamma_{3}=\frac{(1+\delta)(1-\alpha+\mu)-\sqrt{(1+\delta)^{2}(1-\alpha+\mu)^{2}-4 \delta \mu(1+\delta)(1-\alpha)}}{2 \delta \mu} \\
& \gamma_{4}=\frac{(1+\delta)(1-\alpha+\mu)+\sqrt{(1+\delta)^{2}(1-\alpha+\mu)^{2}-4 \delta \mu(1+\delta)(1-\alpha)}}{2 \delta \mu}
\end{aligned}
$$

For these values to be real the model's parameters should verity the following constraint:

$$
\begin{aligned}
& (1+\delta)(1+\alpha+\mu)^{2}>4 \delta(\alpha+\mu), \\
& (1+\delta)(1-\alpha+\mu)^{2}>4 \delta \mu(1-\alpha) .
\end{aligned}
$$

It is true that $\gamma_{1}<\gamma_{2}$ and that $\gamma_{3}<\gamma_{4}$, but also that $\gamma_{1}<\gamma_{3}$. One can conclude that $\gamma_{1}$ is the smallest value $\gamma$ for which a bifurcation may appear. Moreover, one can show through algebraic computations that: $0=\gamma_{1}=1$, implying that $\gamma_{1}$ is a feasible value for $\gamma$ Thus, as $\gamma$ increases from 0 to 1 , the first Hopf bifurcation 
may appear when $\gamma$ reaches $\gamma_{1}$. We therefore check conditions a) and b) for the first couple of eigenvalues $l_{1}, l_{2}$. Further, it will also be proved that the remaining couple of eigenvalues is smaller than one in modulus.

To check the first of the Hopf's necessary conditions, the third power of the eigenvalue associated with $\gamma_{1}$ can be proved to be different from zero. This is derived from the trivial fact that $\ell_{\gamma_{1}}^{3}=\ell_{\gamma_{1}} \ell_{\gamma_{1}}^{2}$.

Since $\ell_{\gamma_{1}}^{2}$ is non zero, $\ell_{\gamma_{1}}^{3}$ is the product of two non-zero factors. On the other hand, $\ell_{\gamma_{1}}^{4}=\left(\ell_{\gamma_{1}}^{2}\right)^{2}$ is a complex number with a non zero complex part. Hence, condition a) holds at $\gamma=\gamma_{1}$.

In what follows, necessary conditions are given for condition b) to hold. As $\left|l_{1}\right|$ $=\left|l_{2}\right|$ in a neighborhood of $\gamma_{1}$, where both are complex, it is also true that $\frac{\partial\left|\ell_{2}\right|}{\partial \gamma}=\frac{\partial\left|\ell_{1}\right|}{\partial \gamma}$, and:

$$
\frac{\partial\left|\ell_{1,2}\right|}{\partial \gamma}=\frac{\mu+\alpha}{2(1+\delta)} \frac{1+\delta(1-\gamma)^{2}}{(1-\gamma)^{2}}[\gamma(\mu+\alpha) H(\gamma)]^{-\frac{1}{2}}>0 .
$$

By continuity, there exists a neighborhood of $\gamma_{1}$ such that $\frac{\partial\left|\ell_{1,2}\right|}{\partial y}>0$.

Finally, it only remains to verify c), i.e. that $l_{3}, l_{4}$ have a modulus smaller than one. We prove condition c) in the interval $\left(0, \gamma_{3}\right)$, which includes the interval $\left(0, \gamma_{1}\right)$. Let us call, $\gamma$ the value of $\gamma$ such that this couple becomes complex: Since $\left|l_{3}\right|<\left|l_{4}\right|$ in $(0, \underline{\gamma})$ it is sufficient to prove that $\left|l_{4}\right|<1$ within this interval. $\left|l_{4}\right|$ is given by:

$$
\left|\ell_{4}\right|=\frac{1}{2}\left(\frac{\gamma \delta}{1+\delta}+\frac{\mu H(\gamma)}{1-\alpha}+\sqrt{\left(\frac{\gamma \delta}{1+\delta}+\frac{\mu H(\gamma)}{1-\alpha}\right)^{2}-4 \frac{\gamma \mu H(\gamma)}{1-\alpha}}\right) .
$$

It is true that since $\left|l_{4}\right|>0$, then $\left|l_{4}\right|<1$ if and only if $\left|l_{4}\right|^{2}<1$. This happens when:

$$
\frac{\mu(1+\alpha(1-\gamma))}{(1+\delta)(1-\alpha)}<1-\frac{\gamma \delta}{1+\delta} .
$$

Since $\alpha+\mu<1$, it follows that $\left|I_{4}\right|<1$ in $(0, \gamma)$.

In the interval $\left(\underline{\gamma}, \gamma_{3}\right), \ell_{3}, \ell_{4}$ are complex, with modulus:

$$
\left|\ell_{3}\right|=\left|\ell_{4}\right|=\sqrt{\frac{\gamma \mu H(\gamma)}{1-\alpha}} .
$$

Its derivative is:

$$
\left|\frac{\partial \ell_{3,4}}{\partial \gamma}\right|=\frac{\mu}{2}\left(\frac{\mu H(\gamma)}{1-\alpha}\right)^{-\frac{1}{2}}\left(\frac{H(\gamma)+\gamma H^{\prime}(\gamma)}{1-\alpha}\right),
$$

where $H^{\prime}(\gamma)=\frac{1}{(1+\delta)(1-\gamma)^{2}}$, which is positive. Therefore $\left|\frac{\partial \ell_{3,4}}{\partial \gamma}\right|>0$. As $\left|l_{4}\right|=1$ at $\gamma_{3}$, then $\left|l_{4}\right|<1$ in $\left(\underline{\gamma}, \gamma_{3}\right)$.

Hence, it has been proved that $\left|l_{3,4}\right|<1$ in $\left(0, \gamma_{3}\right)$, which implies that $\left|l_{3,4}\right|<1$ in $\left(0, \gamma_{1}\right)$ since $\left(0, \gamma_{1}\right) \subset\left(0, \gamma_{3}\right)$. Q.E.D. 


\section{Appendix C}

\section{Proof of proposition 3.}

To prove the proposition, we first prove that $l_{1,2}$ becomes complex for the first time for $\gamma=\hat{\gamma}$ and $l_{3,4}$ at $\gamma=\hat{\gamma} \cdot \hat{\gamma}$ is defined below. Then, to complete the proof, we prove that the moduli of both pairs of eigenvalues are smaller than one in $\left(0, \gamma_{1}\right)$.

We call the function under the radical in the expression for $l_{1,2} F_{1,2}(\gamma)$, defined as:

$$
\begin{aligned}
F_{1,2}(\gamma) & =\left(\frac{\gamma \delta}{1+\delta}+(\mu+\alpha) H(\gamma)\right)^{2}-4 \gamma(\mu+\alpha) H(\gamma) \\
& =\frac{(\gamma \delta(1-\gamma)+(\mu+\alpha)(1+\delta(1-\gamma)))^{2}-4 \gamma(\mu+\alpha)(1+\delta)(1-\gamma)(1+\delta(1-\gamma))}{(1+\delta)^{2}(1-\gamma)^{2}}
\end{aligned}
$$

$F_{1,2}(\gamma)$ has at most four real roots and a vertical asymptote at $\gamma=1 . \hat{\gamma}$ is the closest root to $\gamma_{1}$, with $\hat{\gamma}<\gamma . F_{1,2}(\gamma)$ roots are the points were

$$
(\gamma \delta(1-\gamma)+(\mu+\alpha)(1+\delta(1-\gamma)))^{2}=4 \gamma(\mu+\alpha)(1+\delta)(1-\gamma)(1+\delta(1-\gamma)),
$$

that is, the intersection points of a fourth degree polynomial $P_{4}$ and a third degree polynomial $P_{3}$. For given values of the parameters $\mu, \alpha$ and $\delta, P_{3}$ is negative for $\gamma$ $<0$, positive when $\gamma \in(0,1)$, negative after for a given interval before becoming positive. $P_{4}$ is always positive, reaching its minimum for $\gamma \in(0,1)$. This means that at most, $P_{3}$ and $P_{4}$ have two intersection points within $(0,1)$. The first of these corresponds to $\hat{\gamma}$ and the second one to a value of $\gamma$ larger than $\gamma_{1}$, after which the couple $l_{1,2}$ becomes real. This second point exists given that

$$
\lim _{\gamma \rightarrow 1} \ell_{1,2} \in R \text {. }
$$

To prove that $l_{3,4}$ is a couple of real eigenvalues in $(0, \underline{\gamma})$ and complex in $\left(\underline{\gamma}, \gamma_{3}\right)$, we proceed as before, defining $F_{3,4}$ as:

$$
\begin{aligned}
F_{3,4} & =\left(\frac{\gamma \delta}{1+\delta}+\frac{\mu H(\gamma)}{1-\alpha}\right)^{2}-4 \frac{\gamma \mu H(\gamma)}{1-\alpha} \\
& =\frac{(\gamma \delta(1-\gamma)(1-\alpha)+\mu(1+\delta(1-\gamma)))^{2}-4 \gamma \mu(1-\alpha)(1+\delta)(1-\gamma)(1+\delta(1-\gamma))}{(1-\alpha)^{2}(1+\delta)^{2}}
\end{aligned}
$$

$F_{3,4}$ has at most four real roots which coincide with the values of $\gamma$ where

$$
(\gamma \delta(1-\gamma)(1-\alpha)+\mu(1+\delta(1-\gamma)))^{2}=4 \gamma \mu(1-\alpha)(1+\delta)(1-\gamma)(1+\delta(1-\gamma))
$$

As we did before, we characterize the intersection points between a fourth degree polynomial $P_{4}^{\prime}$ and a third degree polynomial $P_{3}^{\prime}$. These polynomials behave exactly as $P_{3}$ and $P_{4}$, therefore the conclusions are also identical. 
Notice now that $F_{3,4}<F_{1,2}$, and this is true since $\mu+\alpha>\frac{\mu}{1-\alpha}$. Therefore, the pair $l_{3,4}$ becomes first complex, which implies that $\underline{\gamma}<\hat{\gamma}$.

We prove now that $\left|l_{1}\right|$ and $\left|l_{2}\right|$ are smaller than one in $\left(0, \gamma_{1}\right)$, First, observe that $l_{1}<l_{2}$ when they are both real. Therefore, if we prove that $\left|l_{2}\right|<1$ in $(0, \hat{\gamma})$, we obtain immediately the monotonic convergence in $(0, \hat{\gamma})$. Let us write:

$$
\left|\ell_{2}\right|=\frac{1}{2}\left(\frac{\gamma \delta}{1+\delta}+(\mu+\alpha) H(\gamma)+\sqrt{\left(\frac{\gamma \delta}{1+\delta}+(\mu+\alpha) H(\gamma)\right)^{2}-4 \gamma(\mu+\alpha) H(\gamma)}\right) .
$$

If $\left|l_{2}\right|$ were real and attained the value 1 outside the interval $(0,1)$, it would mean that $\left|l_{2}\right|$ is smaller than 1 in $(0, \hat{\gamma})$ This is true since $\left|l_{2}\right|$ is a continuous function. $\left|l_{2}\right|$ attains the value 1 for $\gamma=\frac{1+\delta}{\delta}$, which is larger than $1 \forall \delta$.

It remains to be proved that the couple $l_{1,2}$ also has a modulus smaller than the one when it became complex. The partial derivative of the modulus $l_{1,2}$ was already computed in proposition 2 :

$$
\frac{\partial\left|\ell_{1,2}\right|}{\partial \gamma}=\frac{\mu+\alpha}{2(1+\delta)} \frac{1+\delta(1-\gamma)^{2}}{(1-\gamma)^{2}}[\gamma(\mu+\alpha) H(\gamma)]^{-\frac{1}{2}} .
$$

Since $\gamma$ and $H(\gamma)$ are positive in $\left(\hat{\gamma}, \gamma_{1}\right), \frac{\partial\left|\ell_{1,2}\right|}{\partial \gamma}>0$ in $\left(\hat{\gamma}, \gamma_{1}\right)$. Consequently, $\left|l_{1,2}\right|$ achieves its maximum at $\gamma=\gamma_{1}$.

Regarding the moduli of $\left(l_{3}, l_{4}\right)$, proposition 2 showed that they are smaller than 1 in $\left(0, \gamma_{3}\right)$. Q.E.D.

\section{Appendix I}

\section{Proof of proposition 4.}

The eigenvalues of the system coincide with $l_{1,2}$, already computed in the proof of proposition 2, in Appendix B. Therefore, the point of bifurcation is the same as in the capital mobility case, and equal to $\gamma_{1}$. Hence, the stability properties are also the same. For $\gamma<\hat{\gamma}$ the system converges monotonically, for values of $\gamma$ between $\hat{\gamma}$ and $\gamma_{1}$, convergence is oscillatory. When $\gamma=\gamma_{1}$ the system undergoes a Hopf bifurcation, and it diverges after this value.

To prove that the speed of convergence is slower when capital is immobile, we will show that $\left|l_{1,2}\right|>\left|l_{3,4}\right|$ when $\gamma>\hat{\gamma}$. For these values of $\gamma$, the dynamics of both models (with and without capital mobility) are oscillatory.

$$
\begin{aligned}
& \left|\ell_{1,2}\right|=\sqrt{\gamma(\mu+\alpha) H(\gamma)}, \\
& \left|\ell_{3,4}\right|=\sqrt{\frac{\gamma \mu H(\gamma)}{1-\alpha}} .
\end{aligned}
$$

Then, $\left|l_{1,2}\right|>\left|l_{3,4}\right|$ holds since $\mu+\alpha>\frac{\mu}{1-\alpha}$. Q.E.D. 


\section{Acknowledgments}

We thank an anonymous referee, the editor Oded Galor, the participants to the conference "Irregular growth: Beyond Balanced Growth" (Paris, June 2003), as well as participants to seminars in Ghent and Louvain, Guido Cozzi, Klaus Desmet, Andrew Mountford and Jacques Thisse for valuable comments on an earlier draft. We acknowledge the financial support of the Belgian French-speaking Community (ARC Grant 99/04-235 "Growth and incentive design") and of the Belgian Federal Government (Grant PAI P5/10, "Equilibrium theory and optimization for public policy and industry regulation"). Carmen Camacho acknowledges the support of the Bank of Spain.

\section{References}

Acemoglu, D., S. Johnson, and J. Robinson. (2002). "Reversal of Fortune: Geography and Institutions in the Making of the Modern World Income Distribution." Quarterly Journal of Economics 117(4), 1231-1294.

Bairoch, P. (1991). Cities and Economic Development: From the Dawn of History to the Present. Chicago: University of Chicago Press.

Bairoch, P., J. Batou, and P. Chèvre. (1988). The population of European Cities from 800 to 1850. Genève: $\mathrm{CIEH}$

Barro, R., and X. Sala-I-Martin. (1991). "Convergence Across States and Regions." Brookings Papers on Economic Activity 1, 107-158.

Bockstette, V., A. Chanda, and L. Putterman. (2002). "States and Markets: The Advantage of an Early Start," Journal of Economic Growth 7(4), 347-369.

Brezis, E., P. Krugman, and D. Tsiddon. (1993). "Leapfrogging in International Competition: A Theory of Cycles in National Technological Leadership," American Economic Review 83(5), 1211-1219.

Buiter, W. (1981). "Time Preference and International Lending and Borrowing in an Overlapping Generations Model," Journal of Political Economy 89, 769-795.

Burke, P. (1974). Venice and Amsterdam, a Study of Seventeenth Century Elites. London: Temple Smith.

Clark, A., A. Oswald, and P. Warr. (1996). "Is job satisfaction U-shaped in age?" Journal of Occupational and Organizational Psychology 69(1), 57-81.

de la Croix, D. (1998). "Growth and the Relativity of Satisfaction," Mathematical Social Sciences $36(2), 105-125$.

de la Croix, D. (2001). "Growth Dynamics and Education Spending: The Role of Inherited Tastes and Abilities," European Economic Review 45(8), 1415-1438.

de la Croix, D. and P. Michel. (2002). A Theory of Economic Growth: Dynamics and Policy in Overlapping Generations. Cambridge: Cambridge University Press.

De Vries, J. and A. Van Der Woude. (1997). The First Modern Economy: Success, Failure, and Perseverance of the Dutch Economy, 1500-1815. Cambridge: Cambridge University Press.

Desmet, K. (2002). “A Simple Dynamic Model of Uneven Development and Overtaking," Economic Journal 112(482), 894-918.

Dijk, H. V. and D. Roorda. (1971). "Sociale Mobiliteit Onder Regenten van de Republiek," Tijdschrift voor Geschiedenis 84(2), 306-328.

Engerman, S. and K. Sokoloff. (2002). "Factor Endowments, Inequality, and Paths of Development Among New World Economies," Working Paper 9259, NBER.

Epstein, S. (2000). Freedom and Growth: The Rise of States and Markets in Europe, 1300-1750. London: Routledge. 
Galor, O. (1996). "Convergence? Inferences from Theoretical Models," Economic Journal 106(437), 1056-1069.

Galor, O. and O. Moav. (2002). "Natural Selection and the Origin of Economic Growth," Quarterly Journal of Economics 117(4), 1133-1192.

Galor, O. and D. Weil. (2000). "Population, Technology, and Growth: From the Malthusian Regime to the Demographic Transition and Beyond," American Economic Review 90(4), 806-828.

Galor, O., O. Moav, and D. Vollrath. (2002). "The Origin of Divergence and Overtaking in the Growth Process: Theory and Evidence, CEPR Discussion Paper No. 3817."

Gibbon, E. (1788). The History of the Decline and Fall of the Roman Empire. London: A. Strahan and Cadell.

Hansen, G. and E. Prescott. (2002). "Malthus to Solow," American Economic Review 92(4), $1205-1217$.

Henderson, V. (2003). "The Urbanization Process and Economic Growth: The So-what Question," Journal of Economic Growth 8(1), 47-71.

Kindleberger, C. (1996). World Economic Primacy 1500-1990. New York: Oxford University Press.

Lagerloef, N. P. (2004). "Regional Income Gap in the USA Today-What can Geography and Slavery Explain?" paper presented at the SED conference, Florence.

Landes, D. (1998). The Wealth and Poverty of Nations. London: Little, Brown and Company.

Maddison, A. (1995). Monitoring the World Economy 1820-1992. Paris: OECD.

Mokyr, J. (2002). Gifts of Athena: Historical Origins of the Knowledge Economy. Princeton, NJ: Princeton University Press.

Mountford, A. (1996). "Gradual Convergence Under Perfect International Capital Mobility," Working Paper 9633, Southampton.

Ottaviano, G., T. Tabuchi, and J.-F. Thisse. (2002). "Agglomeration and Trade Revisited," International Economic Review 43(2), 409-435.

Pommeranz, K. (2000). The Great Divergence. Europe, China, and the Making of the Modern World Economy. Princeton: Princeton University Press.

Rappaport, J., and J. Sachs. (2003). "The United States as a Coastal Nation," Journal of Economic Growth 8(1), 5-46.

Ruelle, D. (1989). Elements of Differentiable Dynamics and Bifurcation Theory. New York: Academic Press.

Schiavone, A. (2000). The End of the Past: Ancient Rome and the Modern West. Cambridge Mass.: Harvard University Press. 